\title{
Digital Twin and Shadow in Smart Pork Fetteners
}

\author{
V. ERDÉLYI ${ }^{1}$, L. JÁNOSI ${ }^{2}$ \\ 1Institute Szent István University Institute for Mechanical Engineering Technology, erdely.viktor@gmail.com \\ 2Institute Szent István University Institute for Mechanical Engineering Technology, janosi.laszlo@gek.szie.hu
}

Abstract. This paper introduces our ongoing research in the field of smart livestock farming. The base idea in this research is to take some industry based concepts, and adapt them into agriculture.

In Industry we live the fourth industrial revolution, which is not a technical, but an organization revolution. So in this concept there are two key ideas, which are digital twin, and digital shadow.

This article is about creating digital twin and digital shadow of a modern pig fattener. These models are based on the literature, and are identified on the data shared in these. However, these models can't be used on real systems before identifying them on the actual circumstances.

At this stage of research only digital twin of the product was created, and only some aspects of it. This however can simulate an average porkers feed consumption, weight growth and calculate the weight on certain stages of breeding. Further development is ongoing and our target is to make a fully functional model of a pig fattener.

\section{Introduction}

Nowadays, the concept of Industry 4.0 is becoming more and more known. One of I4.0 core elements is modelling, known as digital twin, and digital shadow. These two are the digital equivalent of not only the production, but the product itself as well. The use of this concept in another production system, such as a pig fattener speaks for itself [2.],[4.].

This paper shows the so far achieved results of the ongoing research. In the smart livestock farming environment, the Digital Twin would be the digital model of the livestock with all the data from it, and the Digital Shadow is the computer counterpart of the production system itself. These, in the industry can be used to achieve predictive maintenance and predictive control which are advantageously affect the production parameters. So to examine its potential in the smart livestock farming, we have to make computer models both of the pigs, the pig fattening process and its assets.

\section{METHODS}

As a first step in the research work, a general model of a pig farm will be designed. The model is based on the measured data found in the literature [3] The parameter identification is based on the same data, however to use the models as an aid to design a pig fattener farm, or use it to control an existing one, further identification is needed based on other farms using the same technologies. These models are intended as commonly usable wireframes. Figure 1 illustrates the structure of the currently used farms where typical time-based control is used. Figure 2, conversely, illustrates a solution where 
control is affected through continuous feedback. Figure 1 illustrates the structure of the currently used farms where typical time-based control is used.

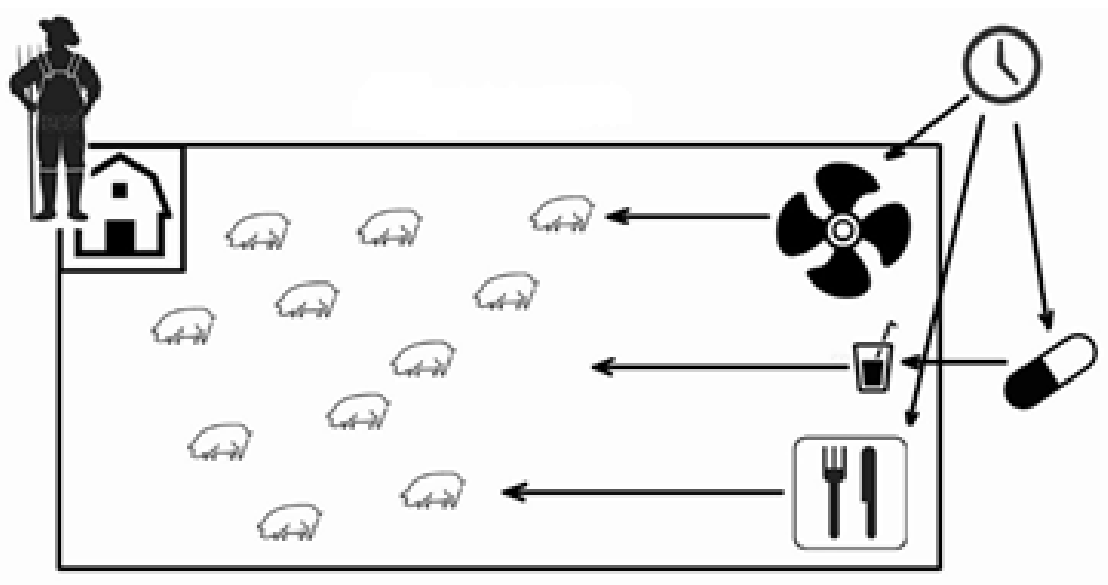

Figure 1. A graphical sketch of the current pig farm model

The model is based on a pig farm of this kind. In these fetters, there are only few fully automated systems using closed control loop. The main feedback is the swineherd himself. Therefore, interestingly it is fairly complicated to model this current solution, it would be much easier, if there were no uncertain factors in control like humans. So in the first steps only the modeling of singular subsystems take place, then these will be interlocked with some uncertainty, based on measured data.

Of course, the best solution would be a feedback coupled system, like on Figure 2, where control is affected through continuous feedback. Fortunately, if the sub models are available, this model will be much easier to build.

The second-degree polynomial based on the weight gain data is the following equation:

$$
\frac{d m}{d t}=a_{m} t^{2}+b_{m} t+c_{m}
$$

The MATLAB polyfit0 method results the following correlation coefficient: $R^{2}=0,99698$.

The effect of feeding is described in the following equation, in which I assumed the simplest case, that only $\mathrm{c}_{\mathrm{m}}$ is concerned, and only linearly (intuition). The equation so prescribed

$$
\mathrm{g}(\mathrm{t}, \mathrm{m})=\mathrm{a}_{\mathrm{g}} \mathrm{t}^{2}+\mathrm{b}_{\mathrm{g}} \mathrm{t}+c_{g} m+\mathrm{d}_{\mathrm{g}}
$$

Parameter identification is done with the data found in literature.

$$
\int_{0}^{\operatorname{tmax}}\left(\mathrm{g}_{\mathrm{m}}-\mathrm{g}(\mathrm{t}, \mathrm{m})\right)^{2} \mathrm{dt} \Rightarrow \min .
$$

The fminsearch() method gave us the correlation coefficient of $R^{2}=0,99677$.

Formula (4) serves to determine parameter $C_{m}$ in formula (1), which is assumed to be a linear relationship. 
International Journal of Engineering and Management Sciences (IJEMS) Vol. 4. (2019). No. 1

$$
\mathrm{C}_{\mathrm{m}}(\mathrm{t})=\mathrm{a}_{\mathrm{c}} \mathrm{g}(\mathrm{t}, \mathrm{m})+\mathrm{b}_{\mathrm{c}} .
$$

The relation (5) shows the substitution of equation (4) in formula (1).

$$
\frac{\mathrm{dm}}{\mathrm{dt}}=\mathrm{a}_{\mathrm{m}} \mathrm{t}^{2}+\mathrm{b}_{\mathrm{m}} \mathrm{t}+a_{c} g(t, m)+b_{c}
$$

Equation (6) used to determine the coefficients of the so-modified (1) equation so it can be written that,

$$
\int_{0}^{\operatorname{tmax}}\left(\mathrm{m}_{\mathrm{m}}-\mathrm{m}_{\mathrm{c}}(\mathrm{t})\right)^{2} \mathrm{dt} \Rightarrow \min
$$

The re-running of fminsearch() algorithm, shows us that the correlation is improved, numerically to $R^{2}=0,99787$.

Italics font expressions indicate the feedback points.

Figure 4. illustrates the solution of these models in Matlab Simulink environment.

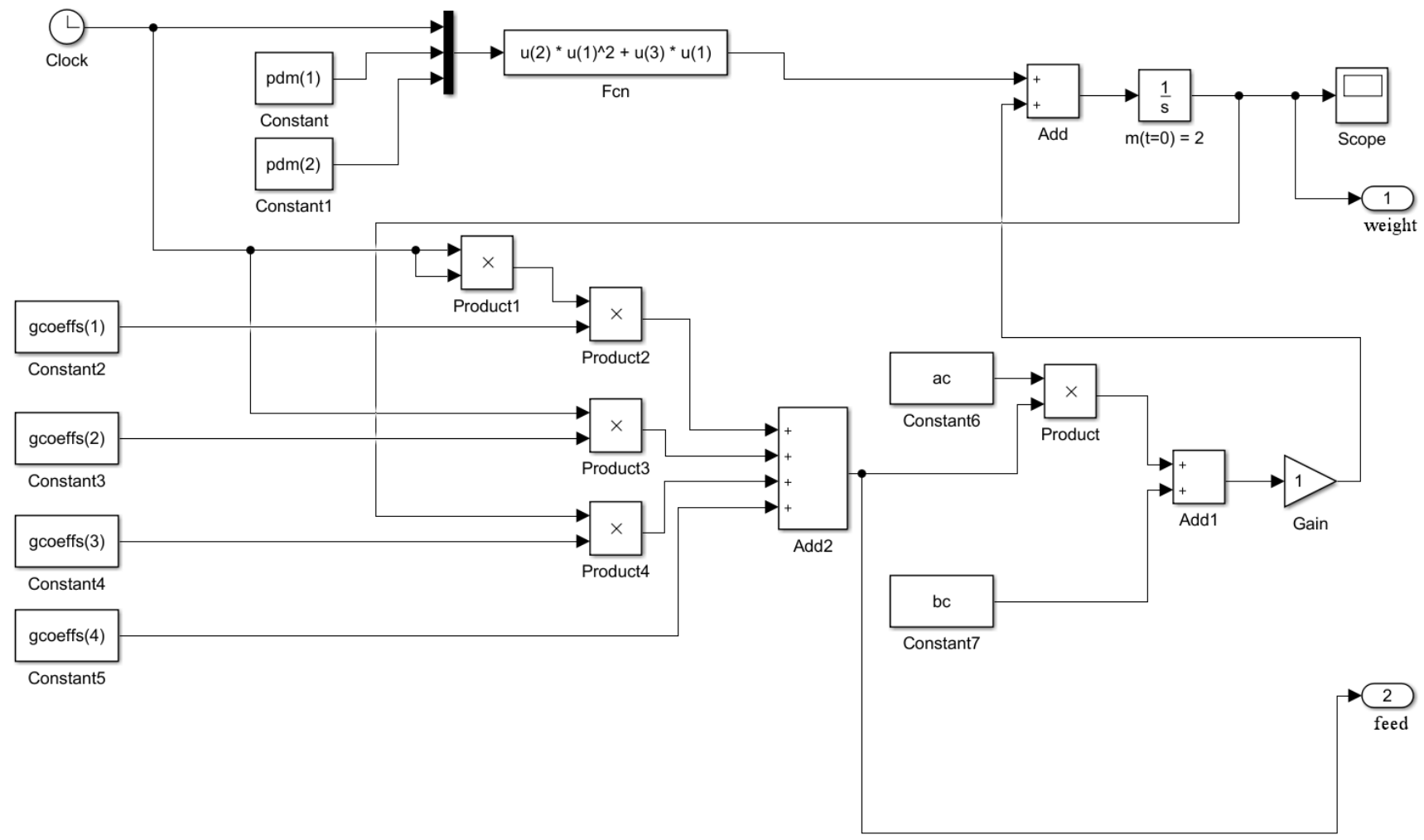

Figure 2. Solution of the porker model in Simulink environment 
Energy balance of pork

$$
\mathrm{cm} \frac{\mathrm{dT}}{\mathrm{dt}}=\eta \mathrm{m}_{\mathrm{t}} \mathrm{H}(\mathrm{m})-\mathrm{kA}\left(\mathrm{T}-\mathrm{T}_{\mathrm{k}}\right)
$$

where:

$\begin{array}{lll}\mathrm{c} & - & \text { specific heat of pig, } \mathrm{J} / \mathrm{kg}^{\circ} \mathrm{C} \\ \mathrm{m} & - & \text { mass of pig, } \mathrm{kg} \\ \mathrm{T} & - & \text { temperature of pig, }{ }^{\circ} \mathrm{C} \\ \mathrm{t} & - & \text { time, } \mathrm{s} \\ \eta & - & \text { nutrient heat utilization efficiency, }- \\ \mathrm{mt} & - & \text { mass of feed, } \mathrm{kg} \\ \mathrm{H} & - & \text { nutrient energy content, } \mathrm{kJ} / \mathrm{kg} \\ \mathrm{k} & - & \text { heat transfer factor, } \mathrm{W} / \mathrm{m}^{2} \\ \mathrm{~A} & - & \text { heat transfer surface of pork, } \mathrm{m}^{2} \\ \mathrm{Tk} & - & \text { ambient temperature, }{ }^{\circ} \mathrm{C}\end{array}$

According to the correlation (8), the energy content of the feed is dependent on the weight of the pig (ruling, 2003):

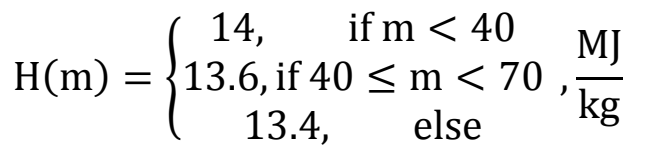

Based on the known density and mass of the pig the volume on an equivalent mass and density sphere could be calculated:

$$
\mathrm{V}=\frac{\mathrm{m}}{\rho}=\frac{4 * \mathrm{r}^{3} * \pi}{3}
$$

from which the sphere radius is expressed as follows:

$$
r=\sqrt[3]{\frac{3 m}{4 \pi \rho}}
$$

where:

$$
\begin{array}{lll}
\mathrm{V} & - & \text { volume of the sphere, } \mathrm{m} 3 \\
\mathrm{r} & - & \text { radius of the sphere, } \mathrm{m} \\
\mathrm{m} & - & \text { mass of the pig, } \mathrm{kg} \\
\rho & - & \text { density of the } \mathrm{pig}, \mathrm{kg} / \mathrm{m} 3
\end{array}
$$

Thus, the surface of the spherical swine model can be expressed as follows:

$$
A=4 r^{2} \pi
$$


where:

A $\quad-\quad$ surface of the sphere, $\mathrm{m} 2$

$r \quad$ - $\quad$ radius of the sphere, $m$

Parameters used at calculations:

$\mathrm{k}=4 \mathrm{~W} / \mathrm{m} 2$

$\eta \quad=10-6$

$\mathrm{c} \quad=260 \mathrm{~J} / \mathrm{kg}^{\circ} \mathrm{C}$

$\mathrm{Tk}=30^{\circ} \mathrm{C}$

$\mathrm{T}(\mathrm{t}=0)=39.3^{\circ} \mathrm{C}$

\section{RESULTS}

The Digital Twin of the porker is under construction. The so far modelled aspect of it are giving the input parameters back if we run the simulation. On Figure 3 the measured values compared to simulated values to be seen. It is interesting, that the growth of the pig can't be described so accurately with an exponential equation, as with a simple second degree polynomic. One possible explanation for this is that the pigs aren't held with ad libitum feeding. Further investigation is in progress.
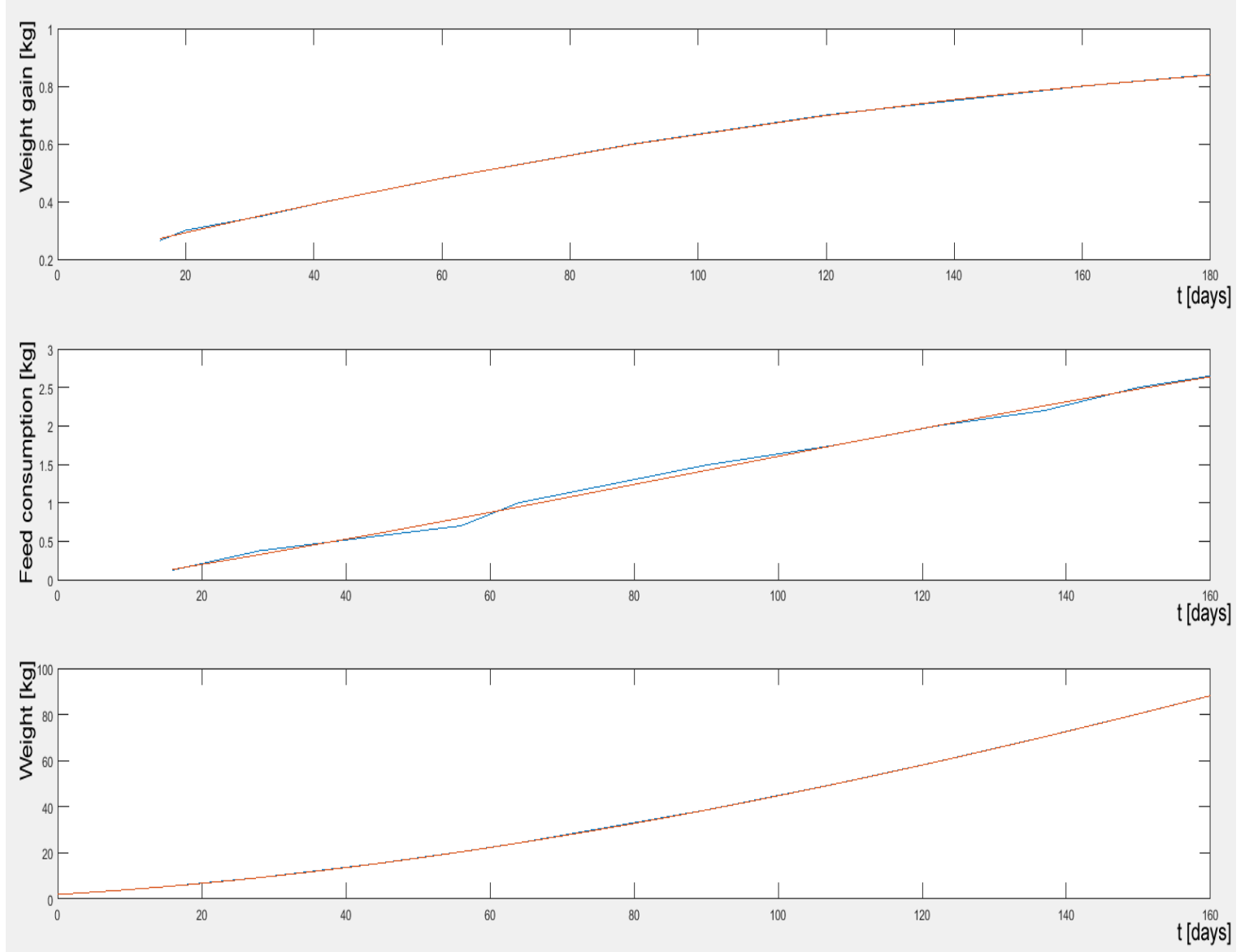

Figure 3. Results of the simulation of the porker model 


\section{CONCLUSIONS}

The build of an existing pig fattener farm - model is now ongoing. This model - after identification and validation- will be used to consider the possibilities of the use of an Industry 4.0 grade closed loop control system. Can it be used without a modification, and if the answer is no, then how should I modify the architecture to gain the output parameters.

In my further work, I will search such solutions, where the subsequent sub-processes of livestock farming are interconnected in a larger master system. That can be stated if the consecutive subsystems are codified, and they can be connected to each other (compatible information contents), then the operation can be optimized in a larger system, and will work more efficiently.

\section{References}

[1] Codex Pabularis Hungaricus (2004)

[2] W. Dieter (2015) Industrie 4.0 - die Zukunft der digitalen Fabrik, VVD-2015 Verarbeitungsmaschinen und Verpackungstechnik, Radebeul.

[3] L. Fenyvesi - L. Mátyás - I. Pazsiczki (2004) Technologies of pig husbandry, Hungarian Institute of Agricultural Engineering. pp. 10-11., Gödöllő, ISBN 963-611-426-9

[4] S. Günter - B. Matthias - R. Jan - B. Martin (2016) Der Digitale Schatten in der Auftragsabwicklung. ZWF Zeitschrift für wirtschaftlichen Fabrikbetrieb. 111 (1-2) pp. 48-51. 